\title{
Trends for beta-blockers use in a large cohort of Polish hypertensive patients - Pol-Fokus Study
}

\author{
Aleksander Prejbisz', Marek Klocek', Jerzy Gąsowski', Roman Topór-Mądry ${ }^{4,5}$, Wiktoria Leśniak ${ }^{6}$, \\ Marek Kabat', Danuta Czarnecka'2, Kalina Kawecka-Jaszcz'ㄹ, Krzysztof Narkiewicz', \\ Andrzej Januszewicz ${ }^{1}$ \\ ${ }^{1}$ Department of Hypertension, Institute of Cardiology, Warsaw, Poland \\ ${ }^{2} 1^{\text {st }}$ Department of Cardiology, Interventional Electrocardiology and Hypertension, Jagiellonian University Medical College, Krakow, Poland \\ ${ }^{3}$ Department of Internal Medicine and Geriatrics, Jagiellonian University Medical College, Krakow, Poland \\ ${ }^{4}$ Faculty of Health Sciences, Jagiellonian University Medical College, Krakow, Poland \\ ${ }^{5}$ Faculty of Health Sciences, Wroclaw Medical University, Wroclaw, Poland \\ ${ }^{6} 2^{\text {nd }}$ Department of Internal Medicine, Jagiellonian University Medical College, Krakow, Poland \\ ${ }^{7}$ Department of Diabetology and Hypertension, Medical University of Gdansk, Gdansk, Poland
}

\section{Summary}

Background Beta-blockers remain one of the most frequently prescribed antihypertensive drug classes. The aim of the analysis was to evaluate characteristics of patients treated with beta-blockers and factors associated with the treatment of beta-blockers.

Material and methods We analysed the data from the large cross-sectional study evaluating 12,375 patients treated for hypertension for at least one year

Results Overall, 7080 patients ( $57.2 \%$ of the whole group) were treated with beta-blockers. The rate of use of beta-blockers was higher in patients with diabetes (62.9 vs $55.6 \%)$, coronary artery disease $(72.2$ vs $46.4 \%)$, previous myocardial infarction $(82.3$ vs $54.1 \%)$, heart failure (73.1 vs $53.3 \%$ ) and arrhythmias ( 73.1 vs $51.1 \%)$ than in patients without those conditions (all comparisons $\mathrm{p}<0.001$ ). Beta-blockers were used less frequently among patients with asthma/COPD than without asthma/COPD (54.0 vs 58.0\%; $\mathrm{p}=0.017$ ). In patients aged 40 years and less, the compelling indications for these agents were found only in $21.7 \%$ of patients. In patients aged $40-65$ years, none of compelling indications was found in $41.3 \%$ of patients. In patients 65 years or more, the most frequent compelling indications were coronary artery disease, previous myocardial infarction and heart failure, which were present in $70.1 \%$ of patients.

Conclusions High utilization rate of beta-blockers in patients with hypertension, only second to renin-angiotensin blockers, has been shown. In middle age and, especially, in older patients it might reflect high cardiovascular burden of those patients, including coexistence of established cardiac disease. In younger patients beta-blockers are used more frequently with none of the compelling indications present.

key words: beta-blockers, hypertension, guidelines

Arterial Hypertens. 2015, vol. 19, no. 3, pages: 120-128

DOI: $10.5603 / A H .2015 .0015$

Address for correspondence: Aleksander Prejbisz, M.D., Ph.D.

Department of Hypertension, Institute of Cardiology

Alpejska 42, 04-628, Warsaw

Phone +48 223434 339; Fax + 48223434 517; e-mail a.prejbisz@ikard.pl

V M Copyright @ 2015 Via Medica, ISSN 2449-6170 


\section{Background}

In the European Society of Hypertension/European Society of Cardiology (ESH/ESC) 2013 guidelines as well as in the guidelines of the Polish Society of Hypertension 2015, beta-blockers were maintained as a possible choice for antihypertensive treatment and were listed among five major antihypertensive drug classes [1-3]. However, some meta-analyses have reported that beta-blocker may be inferior to some other classes for the reduction of total mortality and cardiovascular events. Based on those data, some international guidelines did not include beta-blockers to the first-line antihypertensive treatment [4-6].

Despite those controversies, recent surveys have shown that beta-blockers remain one of the most frequently used groups of antihypertensive drugs, second or third to the most popular renin-angiotensin system blockers. The rate of use of beta-blockers remained stable or even increased in surveys evaluating changes in the rate of use of antihypertensive medications over past decade [7-10].

The Pol-Fokus study aimed to evaluate characteristics of hypertensive patients in Poland and factors related to blood pressure (BP) control in a large sample of hypertensive patients treated for at least one year under the care of general practitioners (GPs) and specialists (cardiologists and hypertension specialists) all over Poland [11]. The aim of the presented analysis was to present clinical characteristics of hypertensive patients treated with beta blockers. We also analysed the prevalence of beta-blockers use in different subgroups of patients in which this class of antihypertensive drugs should be preferred and considered.

\section{Material and methods}

The methodology of the Pol-Fokus study was already published [11]. In summary, Pol-Fokus was a large, observational, cross-sectional survey of hypertensive subjects followed up by GPs, cardiologists and hypertension specialists throughout the Polish territory. The study was approved by the Ethics Committee of the Jagiellonian University, in Krakow, Poland and all participants provided informed consent. Nine hundred and seventy-eight GPs and 286 specialists (cardiology or hypertensiology) from all provinces in Poland participated in the Pol-Fokus study. The methods of selection of this group has been already described in details [11].

The Pol-Fokus study included hypertensive patients meeting the following criteria: age 18 years or more, hypertension treated for at least one year, with at least one visit to the doctor, participating in the study over the last year. They had to be free from any acute disease in the preceding 4 weeks and free from known secondary causes of hypertension. After discarding data from doctors who did not achieve the specific quota or who provided incomplete questionnaires, as well as patients who were included despite not meeting the inclusion criteria and patients with no data regarding antihypertensive treatment, we finally analysed data from 12,375 patients [11].

All patients underwent standard clinical evaluation. The known duration of the hypertension was recorded. Weight and height as well as waist circumference were measured. Body mass index (BMI) was calculated. Abdominal obesity was defined as a waist circumference $>102 \mathrm{~cm}$ and $>88 \mathrm{~cm}$, for women and men respectively $[2,12]$. Current antihypertensive medications were also documented. Plasma sodium, potassium, glucose, creatinine and total cholesterol, low density lipoprotein (LDL) cholesterol, high density lipoprotein (HDL) cholesterol and triglycerides concentration, history of coronary artery disease (CAD), previous myocardial infarction, heart failure, arrhythmias, cerebrovascular diseases (CVD, including previous transient ischemic attack or stroke), asthma or chronic obstructive pulmonary disease (COPD), depression or anxiety, diabetes and other diseases were assessed. Each participating doctor was provided with specific instruction for these assessments. The estimated glomerular filtration rate (eGFR) was calculated according to the Modification of Diet in Renal Disease (MDRD) study formula [13]. Cardiovascular risk (stratification into 4 groups: low, moderate, high and very high added risk) as well as metabolic syndrome were evaluated according to the criteria of the $2013 \mathrm{ESH} / \mathrm{ESC}$ guidelines [2].

$\mathrm{BP}$ was measured with a patient in the sitting position after a 5 min rest. Based on upper arm circumference, an appropriately sized cuff was placed on the arm with the lower edge of the cuff $2 \mathrm{~cm}$ above the antecubital fossa. Three consecutive readings were performed. The average of these three readings was recorded. Each participating doctor was provided with detailed instruction for BP measurement. Use of devices with proofed accuracy was recommended.

We defined hypertension control as BP levels both lower than $140 \mathrm{~mm} \mathrm{Hg}$ for systolic and lower than $90 \mathrm{~mm} \mathrm{Hg}$ for diastolic blood pressure [2].

Data analysis was carried out using the statistical software PASW Statistics 18 (SPSS Inc., Chicago, IL, USA). The results are presented as mean \pm one stan- 
dard deviation, or median and interquartile range. The values of variables were compared between groups - continuous and discrete variables: Student's t test, Mann-Whitney test or univariate ANOVA analysis with Duncan post-hoc test; categorical variables: chi $^{2}$ test or Fisher exact test. Multivariate logistic regression models were performed, in order to determine the combined effect of several variables on the prevalence of the characteristic. For multivariate analysis the variables with significant association were included. Multicollinearity was checked by variation inflation factor. $\mathrm{P}<0.05$ was considered statistically significant.

\section{Results}

As described previously, we included 12,375 patients (mean age $64.0 \pm 12.3$ years; age range $18-98$ years; $59 \%$ females) [11]. Overall, 7080 patients $(57.2 \%$ of the whole group) were treated with beta-blockers. Among 5 major classes of antihypertensive drugs beta-blockers were the second most frequently used antihypertensive group after angiotensin converting enzyme (ACE) inhibitors $(61.3 \%$ of the whole group) and before thiazide/thiazide-type diuretics, calcium channel blockers and angiotensin II receptor blockers (ARBs) (respectively: 48.0\%, 36.5\% and $35.3 \%)$. Among hypertensive patients on monotherapy beta-blockers were the third most frequently used antihypertensive group after ACE inhibitors and ARBs (Figure 1).

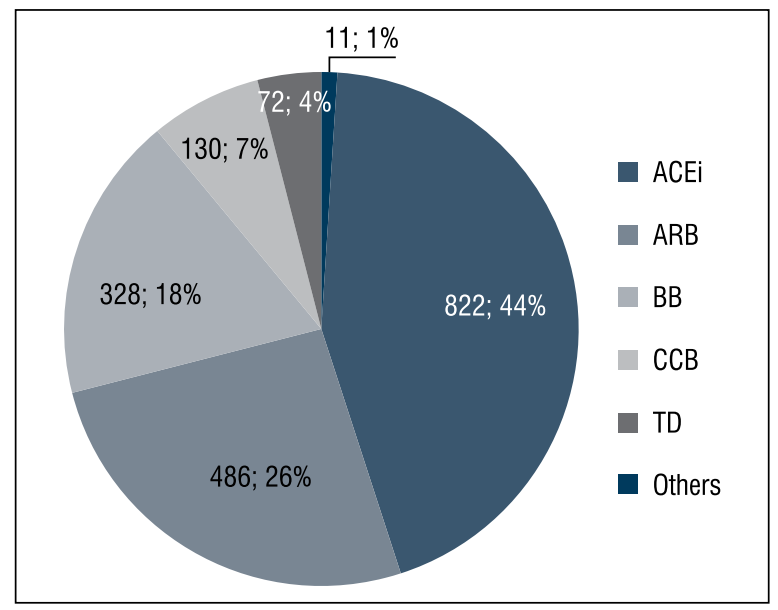

Figure 1. Rate of use of antihypertensive drugs among patients on one antihypertensive drug. Data are presented as a number of patients and rate

ACEi - angiotensin converting enzyme inhibitor, ARB - angiotensin II receptor blocker, BB - beta-blocker, CCB - calcium channel blocker, $\mathrm{n}$ - number of patients, TD - thiazide/thiazide-type diuretic
Patients treated with beta-blockers were characterized by higher: age, BMI, frequency of abdominal obesity, pulse pressure, median number of antihypertensive drugs, plasma concentrations of triglycerides and glucose and lower concentrations of total and LDL cholesterol as well as by lower eGFR (Table 1). There were no differences between patients treated with beta-blockers and not treated with beta-blockers in systolic and diastolic BP level and in the rate of hypertension control as well as in plasma concentration of sodium, potassium, HDL cholesterol, and creatinine (Table 1 ).

We analysed the rate of use of beta-blockers in 3 age categories (40 years and less, 40-65 years and 65 years and more) (Figure 2). Overall, beta-blockers were used more frequently in the 40-65 years and 65 and more years groups. Among patients on monotherapy there was no difference in the rate of use of beta-blockers among the three age groups. Among patients on 2 antihypertensive drugs beta-blockers in combination with renin-angiotensin blockers were used most frequently in the 40-65 years group. Among patients on 3 antihypertensive drugs, the combination of a beta-blocker, a renin-angiotensin blocker and a thiazide/thiazide-type diuretic was used more frequently in the 40 years and less group and in the 40-65 years group (Figure 2). Among age categories 40-65 years and 65 years and more, beta-blockers were used more frequently in patients with high and very high cardiovascular risk than in patients with low and moderate cardiovascular risk. Among patients 40 years and less, the rate of use of beta-blockers was not related to the cardiovascular risk level (Figure 3).

The rate of use of beta-blockers was higher in patients with metabolic syndrome, diabetes, coronary artery disease, previous myocardial infarction, heart failure, arrhythmias, cerebrovascular disease and eGFR lower than $60 \mathrm{ml} / \mathrm{min} / 1,73 \mathrm{~m}^{2}$ than in patients without those conditions (Figure 4). Beta-blockers were used less frequently among patients with asthma/COPD than without asthma/ /COPD (54.0 vs $58.0 \%$; p = 0.017). Among patients with anxiety/depression, the rate of use of beta-blockers was higher than among patients without anxiety/depression $(62.1 \%$ vs $56.6 \%$; $<<0.001)$.

Rate of specific conditions in which beta-blockers might be preferred: heart failure, previous myocardial infarction (without heart failure), arrhythmias (excluding patients with heart failure and previous myocardial infarction) and coronary artery disease (excluding patients with heart failure, previous myocardial infarction and arrhythmias) in all patients treated with beta-blockers and in patients treated with be- 
Table 1. Characteristics of patients treated or not with beta-blockers in the studied group

\begin{tabular}{|c|c|c|c|c|}
\hline & $\mathbf{N}$ & Treated with beta-blocker & Untreated with beta-blocker & $\mathbf{P}$ \\
\hline Number & 12375 & 7080 & 5295 & \\
\hline Gender ( $\%$ of $\mathrm{F})$ & 12375 & 58.5 & 59.7 & 0.19 \\
\hline Age (years) & 12375 & $64.9 \pm 11.7$ & $62.8 \pm 12.9$ & $<0.001$ \\
\hline $\mathrm{BMI}\left[\mathrm{kg} / \mathrm{m}^{2}\right]$ & 12094 & $29.3 \pm 4.7$ & $28.5 \pm 4.5$ & $<0.001$ \\
\hline Abdominal obesity (\%) & 12264 & 56.5 & 50.5 & $<0.001$ \\
\hline Systolic BP [mm Hg] & 12375 & $140 \pm 16$ & $140 \pm 15$ & 0.29 \\
\hline Diastolic BP [mm Hg] & 12375 & $84 \pm 11$ & $84 \pm 13$ & 0.087 \\
\hline Pulse pressure $[\mathrm{mm} \mathrm{Hg}]$ & 12375 & $56 \pm 13$ & $55 \pm 15$ & 0.011 \\
\hline Number of antihypertensive drugs (n) & 12375 & $3(2-4)$ & $2(1-3)$ & $<0.001$ \\
\hline Controlled HT (\%) & 12375 & 47.0 & 47.8 & 0.38 \\
\hline Sodium $[\mathrm{mmol} / \mathrm{L}]$ & 7230 & $140.1 \pm 3.7$ & $140.1 \pm 3.9$ & 0.41 \\
\hline Potassium [mmol/L] & 7911 & $4.4 \pm 0.4$ & $4.4 \pm 0.4$ & 0.21 \\
\hline Creatinine concentration $[\mu \mathrm{mol} / \mathrm{L}]$ & 8669 & $90.5 \pm 42.6$ & $88.0 \pm 33.9$ & 0.18 \\
\hline eGFR $\left[\mathrm{ml} / \mathrm{min} / 1.73 \mathrm{~m}^{2}\right]$ & 8708 & $72.4 \pm 23.4$ & $74.0 \pm 23.9$ & 0.002 \\
\hline Glucose $[\mathrm{mmol} / \mathrm{L}]$ & 10647 & $5.78 \pm 1.38$ & $5.58 \pm 1.28$ & $<0.001$ \\
\hline Total cholesterol [mmol/L] & 9406 & $5.31 \pm 1.11$ & $5.45 \pm 1.07$ & $<0.001$ \\
\hline LDL cholesterol [mmol/L] & 8710 & $3.14 \pm 0.97$ & $3.27 \pm 0.93$ & $<0.001$ \\
\hline HDL cholesterol [mmol/L] & 8806 & $1.39 \pm 0.77$ & $1.42 \pm 0.62$ & 0.051 \\
\hline Triglycerides $[\mathrm{mmol} / \mathrm{L}]$ & 9734 & $1.68 \pm 0.67$ & $1.65 \pm 0.63$ & 0.012 \\
\hline
\end{tabular}

The results are presented as mean \pm one standard deviation or median and interquartile range in the parenthesis. Categorical variables are shown as frequencies. 1 - for comparison between 3 groups, 2 - for comparison between patients with controlled and uncontrolled hypertension, 3- for comparison between patients with controlled and resistant hypertension

$\mathrm{BMI}$ — body mass index, $\mathrm{BP}$ — blood pressure, eGFR — estimated glomerular filtration rate, $\mathrm{F}$ — females, $\mathrm{HDL}$ — high density lipoprotein, $\mathrm{HT}$ — hypertension, LDL — low density lipoprotein, $\mathrm{M}$ — males

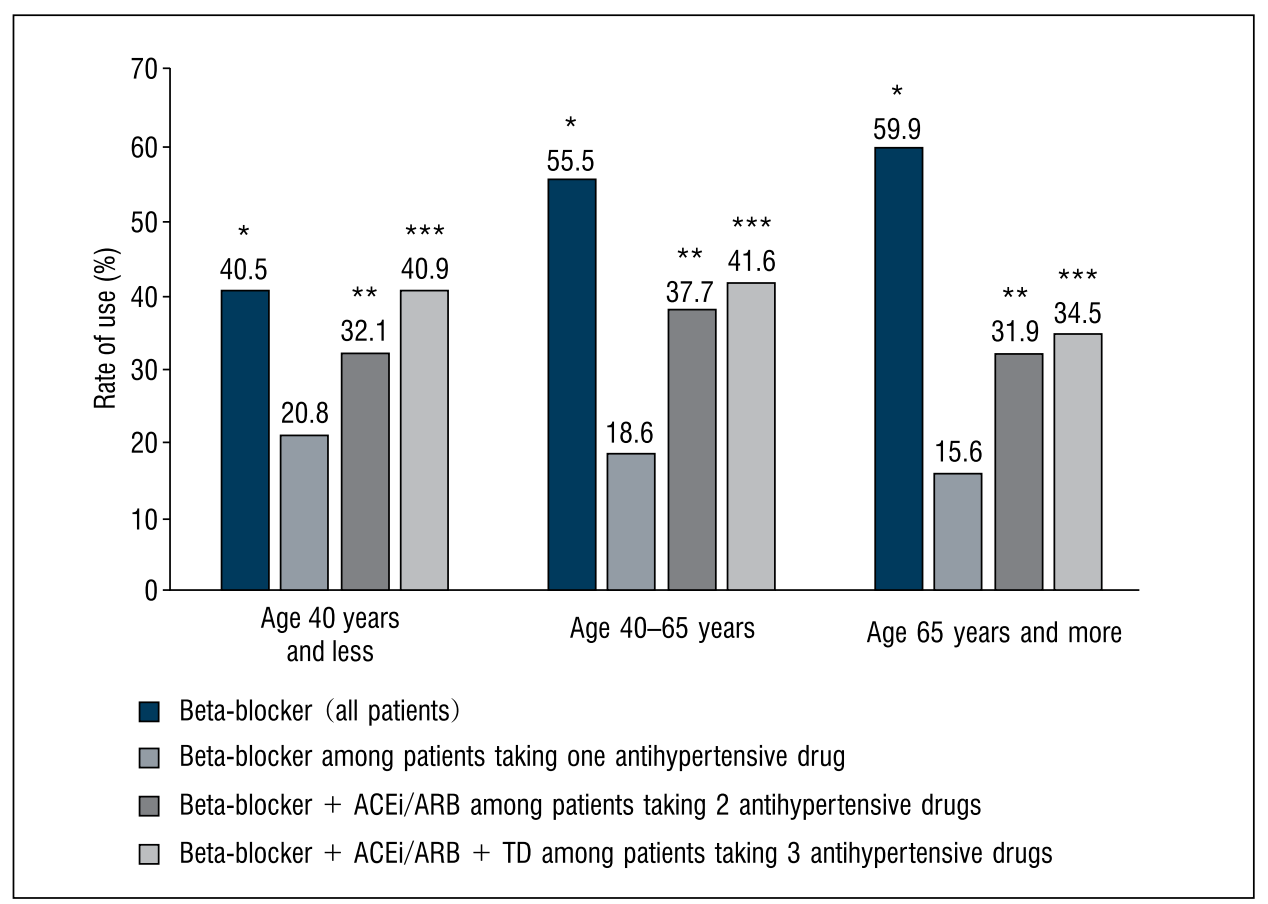

Figure 2. Rate of use of the beta-blockers (\%) in all patient and in patient receiving monotherapy, rate of use of combination of angiotensin converting enzyme inhibitor or angiotensin II receptor blocker and beta-blocker (\%) among patients receiving 2 antihypertensive drugs and rate of use of combination of angiotensin converting enzyme inhibitor or angiotensin II receptor blocker and beta-blocker and thiazide/thiazide-type diuretic (\%) among patients receiving 3 antihypertensive drugs across the age categories $<40$ years, $40-65$ years and $\geq 65$ years $*^{* *},{ }^{* *}-p<0.001$ for the differences across the age categories $<40$ years, $40-65$ years and $\geq 65$ years ACEi - angiotensin converting enzyme inhibitor, ARB — angiotensin II receptor blocker, TD — thiazide/thiazide-type diuretic 


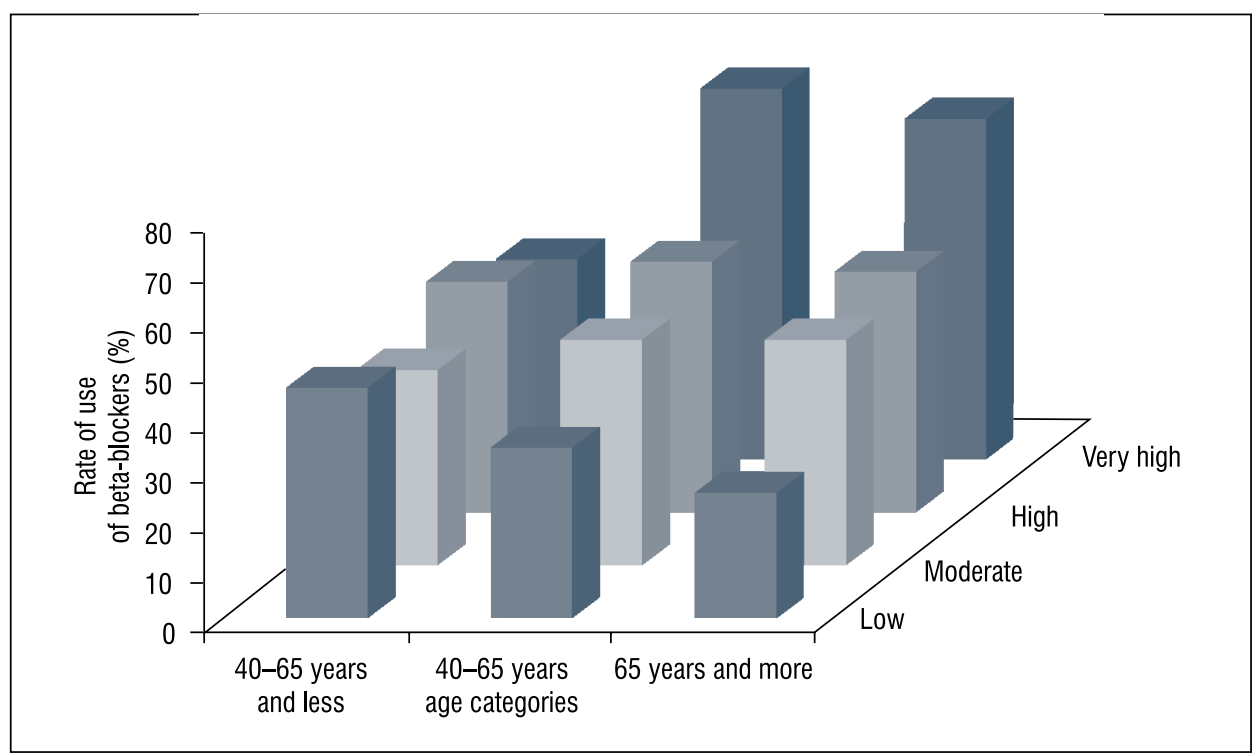

Figure 3. Rate of use of beta-blockers in relation to cardiovascular risk stratification in according to the $2013 \mathrm{ESH} / \mathrm{ESC}$ guidelines across the age categories $<40$ years, $40-65$ years and $\geq 65$ years

ESH/ESC - European Society of Hypertension/European Society of Cardiology

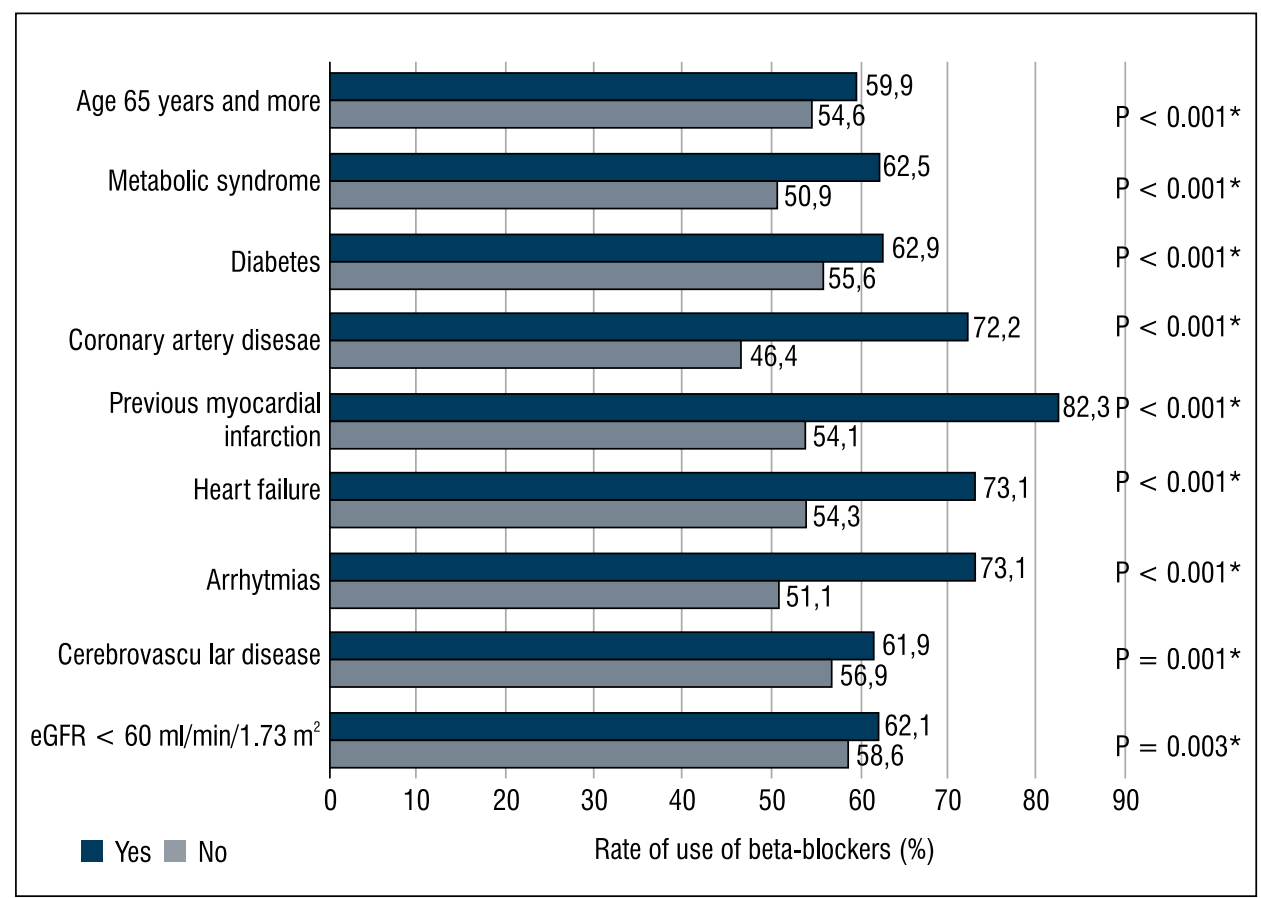

Figure 4. Rate of use of the beta-blockers (\%) in relation to coexisting clinical conditions in the studied group ${ }^{*} \mathrm{P}$ value for comparison between patients with and without coexisting clinical condition eGFR — estimated glomerular filtration rate, HT — hypertension

ta-blockers across the age categories $<40$ years, $40-65$ years and $\geq 65$ years were evaluated (Figure 5 ). In all patients treated with beta-blockers the most frequent conditions were coronary artery disease and heart failure (Figure 5A). In patients aged 40 years and younger, those conditions were found only in $21.7 \%$ of patients (Figure 5B). In patients aged $40-65$ years, the most frequent conditions were coronary artery disease and arrhythmias, however none of the listed above conditions was found in $41.3 \%$ of patients (Figure 5C). In older patients treated with beta-blockers, the most frequent conditions were coronary artery disease, previous myocardial infarction and heart failure present in $70.1 \%$ of patients (Figure 5D). 
A. All patienst

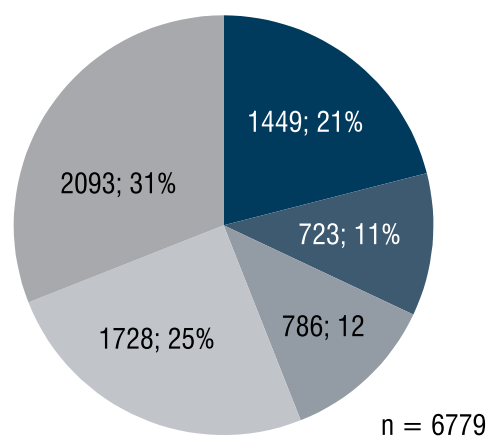

C. Patients $40-65$ years

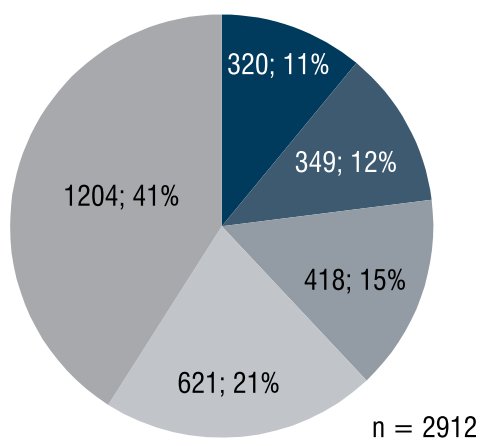

B. Patents 40 years and younger

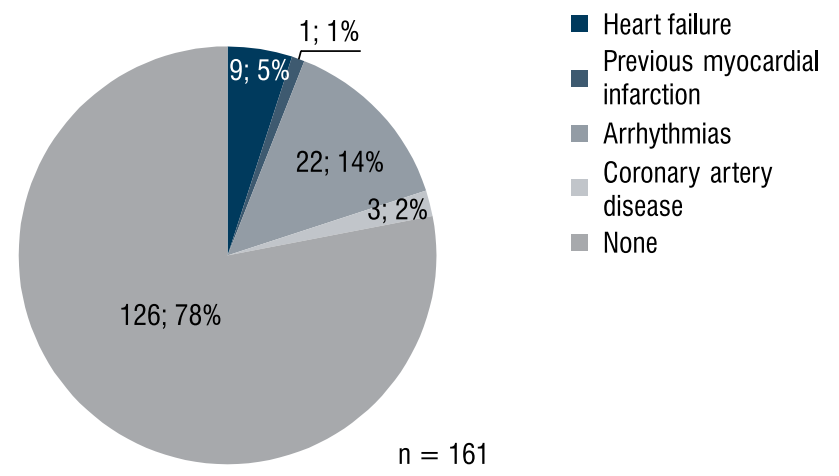

D. Patents 65 years and more

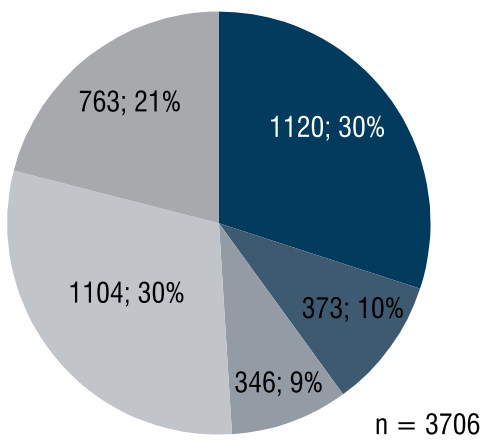

Figure 5. Rate of specific conditions in which beta-blockers might be preferred: heart failure, previous myocardial infarction (without heart failure), arrhythmias (excluding patients with heart failure and previous myocardial infarction) and coronary artery disease (excluding patients with heart failure, previous myocardial infarction and arrhythmias) in all patients treated with beta-blockers $(\mathbf{A})$ and in patients treated with beta-blockers across the age categories $<40$ years (B), 40-65 years (C) and $\geq 65$ years (D)

We performed multivariate models (including gender, age, pulse pressure, abdominal obesity, metabolic syndrome, diabetes, coronary artery disease, previous myocardial infarction, heart failure and arrhythmias) to assess independent association of factors with the treatment with beta-blockers in the whole studied group and across the age categories $<40$ years, 40-65 years and 65 years and more. Only abdominal obesity or metabolic syndrome and arrhythmias were independently associated with beta-blockers use in the whole group and across all age categories (Table 2). Coronary artery disease and previous myocardial infarction were associated independently with beta-blockers use in patients 40-65 years and in patients 65 year and more. In the latter group also heart failure was independently associated with beta-blockers use.

\section{Discussion}

Beta-blockers have long been used as a first-line therapy for hypertension because they were thought to have long-term favourable effects on all-cause and cardiovascular mortality, but the robustness of the evidence for initiating antihypertensive therapy with beta-blockers has been challenged [14]. Moreover as summarized by the ESH/ESC 2013 guidelines, none of the preferred 2 drugs combination is based on beta-blockers. Although the thiazide diuretic-beta-blocker combination has been shown to be effective in cardiovascular risk reduction, this combination appears to elicit more cases of new-onset diabetes in susceptible individuals, compared with other combinations. Therefore this combination has been described as "useful combination (with some limitations)" [2, 15]. However Polish Society of Hypertension 2015 guidelines listed two combinations containing a beta-blocker (with an ACE inhibitor or a calcium channel blocker) as preferred combinations [3].

Our study showed that despite those concerns the rate of use of beta-blockers in Poland remains relatively high (57.2\%) and this group of antihypertensive drugs remains one of the most often selected antihypertensive medication classes used for the treatment of hypertension only second to renin-an- 


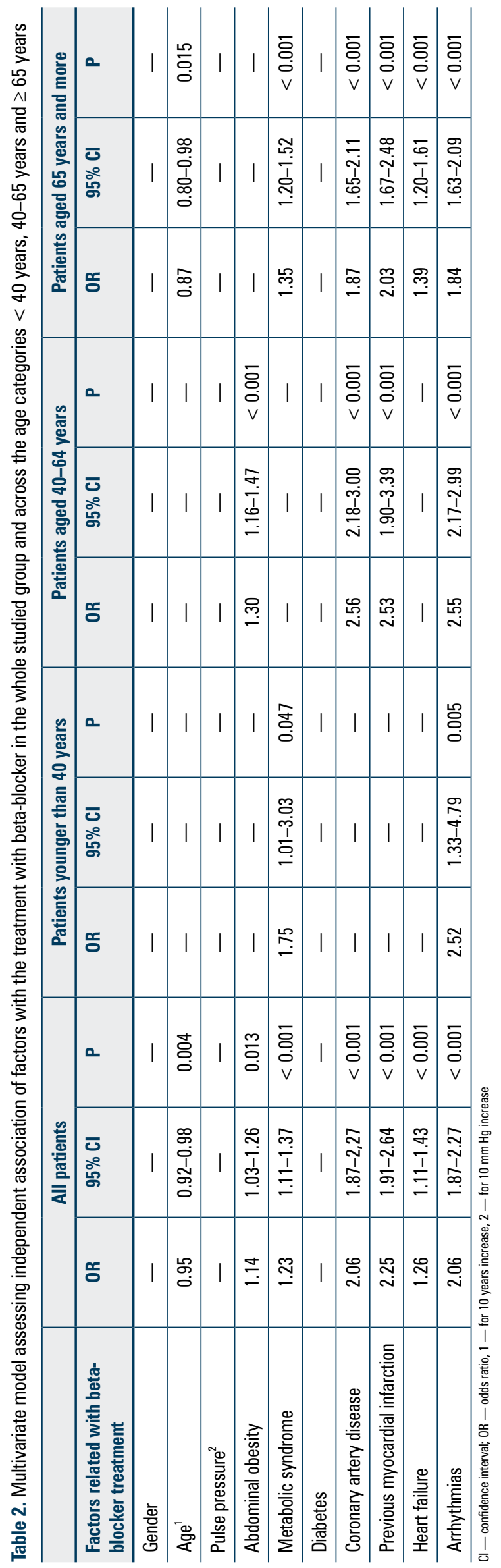

giotensin blockers (ACE inhibitors and ARBs). Beta-blockers were used more frequently in polytherapy regimens than in monotherapy. The recent data from German Health Examination Surveys showed high rate of beta-blockers use, rising from 39\% in 1998 to $54 \%$ in $2008-2011$ [7]. In the evaluation of the United States National Health and Nutrition Examination Survey (NHANES), the overall prevalence of use of beta-blockers increased from $20.3 \%$ in NHANES 2001 to 2002 to $31.9 \%$ in NHANES 2009 to 2010 (the rates were given for all hypertensive patients - both treated and untreated). This was mainly driven by a $65 \%$ increase in the use of beta-blockers used in polytherapy regimens to treat hypertension [10]. Also other studies showed similar trends for beta-blocker use in hypertensive patients $[8,9]$.

Beta-blockers are recommended when hypertension is associated with certain compelling co-morbidities. In post-myocardial infarction setting, beta-blockers decrease recurrent myocardial infarction and improve survival. They have been also shown to improve functional class, reduce frequency of hospitalization and improve survival in patients with heart failure [14]. In our studies those conditions were found in respectively $21 \%$ and $11 \%$ of patients on beta-blockers. Moreover, respectively $82 \%$ and $73 \%$ of patients with those conditions were taking beta-blockers. Thus we showed high utilization of this group in conditions where benefits of beta-blocker are proven. Our results also underline that patients with hypertension are characterized by pronounced cardiovascular burden and frequent concomitant cardiovascular disease requiring beta-blockers' use.

Our study showed that the rate of use of beta-blockers in patients with asthma/COPD was lower than in patients without these conditions. Historically, beta-blockers have sometimes been withheld from asthma or COPD patients. Taking into account that most of the patients in this group in our study had COPD, it should be noted that several studies including COPD and beta-blocker treatment found a protective effect of beta-blockers on all-cause mortality both in primary or secondary prevention [16]. Thus emphasis should be placed on higher awareness of benefits of beta-blocker treatment in patients with COPD. Nevertheless, these agents should be used with caution in patients with pulmonary disease [14].

There is concern that beta-blockers may impair glycaemic control by reducing insulin sensitivity and mask hypoglycaemia. However, beta-blockers may produce greater improvements in cardiovascular outcome among diabetic patients compared with those without diabetes. Treatment with third-generation 
beta-blockers does not appear to be associated with changes in glycaemic control and may improve insulin sensitivity [14, 17]. We found that the rates of use of beta-blockers were higher both in patients with diabetes or metabolic syndrome as compared with patients without those symptoms. Although we were not able to differentiate which particular agents were used, current guidelines advise that additional receptor mediated effects (alpha1-adrenergic receptor blockade by carvedilol, beta3-adrenergic receptor activation by nebivolol), beneficial effects on metabolic parameters and endothelial function, and the results of large-scale clinical trials all suggest that vasodilating beta-blockers should be preferred if a beta-blocker is indicated in hypertensives with diabetes or metabolic syndrome [3].

Beta-blockers are the drugs of first choice for the treatment of hypertension in patients with coronary artery disease that causes angina [18]. However, no large trails have been performed to assess their effectiveness in reducing major cardiac events in patients with stable coronary disease without prior myocardial infarction. In a large study based on evaluation of electronic health records, it has been shown that use of beta-blockers among patients with new-onset coronary artery disease was associated with lower risk of cardiac events only among patients with a recent myocardial infarction [19]. Also in the post hoc analysis from the Clopidogrel for High Atherothrombotic Risk and Ischaemic Stabilization, Management, and Avoidance (CHARISMA) trial showed that beta-blocker use is not associated with lower cardiovascular events in those with coronary artery disease without prior myocardial infarction, with suggestion of inferior outcome with regard to stroke risk [20]. However, these findings have not been conferred in the guidelines [1-3]. In our study, stable coronary artery disease without prior myocardial infarction was the most frequent compelling indication for the utilization of beta-blockers. This finding in the light of uncertain cardioprotective effect emphasize the need of further studies aimed on evaluation of these agents benefits in patients with stable coronary artery disease without prior myocardial infarction.

The anti-arrhythmic properties result from decreased sympathetic and heart rate activity and increased cardiac vagal tone. According to current guidelines, use of beta-blockers in the treatment of hypertension is recommended in patients with arrhythmias $[2,3,14]$. Our study showed high utilization of these agents in patients with arrhythmia as well as that arrhythmias remain a compelling indication for use of these agents in hypertensive subjects, especially younger than 40 years and in the age group of 40-65 years.
The use of beta-blockers remains the subject of debate. They are no more effective than other antihypertensive agents and, according to some recent analysis, they failed to reduce myocardial infarction while providing less protection against strokes. This is particularly true for atenolol [21-23]. Nevertheless, the current Polish Society of Hypertension guidelines upheld the position taken in the previous guidelines that beta-blockers should remained among first-line antihypertensive drugs, stressing that that vasodilating agents (carvedilol, nebivolol) due to their haemodynamic properties (smaller negative chronotropic effect and a reduction of total peripheral resistance), resulting in a more favourable effect on central aortic pressure, should be preferred among beta-blockers in patients with uncomplicated hypertension. This has been also reflected in the text of the $2013 \mathrm{ESH} /$ /ESC guidelines that noted some beneficial aspects of the mechanism of action of vasodilating beta-blockers [1-3]. Our study showed high rate of patients on beta-blockers with none of the compelling indications discussed above in younger patient but not in older patients (especially those over 65 years). In patients older than 40 years use of beta-blockers was related to the level of cardiovascular risk it was not true for patients younger than 40 in whom no relation between level of cardiovascular risk and utilization of these agents was found. Although we were not able to assess the particular drugs used, more emphasis should be put on the use of vasodilating beta-blockers in younger patients in whom beta-blockers are frequently used with none of the compelling indications present.

\section{Conclusions}

Our study based on a large group of treated hypertensive patients has shown high utilization rate of beta-blockers in patients with hypertension, only second to renin-angiotensin blockers. In middle age and, especially, in older patients it might reflect high cardiovascular burden of those patients, including coexistence of established cardiac disease. In younger patients beta-blockers are used more frequently with none of the compelling indications present.

\section{Acknowledgements}

The study was funded by an unrestricted scientific grant from KRKA

\section{Conflict of interest}

$\mathrm{AP}$ reports having received lecturer's honoraria and travel expenses from Servier, Krka, Berlin-Chemie/ /Menarini, Polpharma, Medtronic and Zentiva. 
MK reports having received lecturer's honoraria and travel expenses from Krka, Berlin-Chemie/ Menarini, Zentiva.

KKJ reports having received lecturer's honoraria from Polpharma and travel expenses from Servier.

$\mathrm{KN}$ reports having received lecturer's honoraria and travel expenses from Servier, Krka, Berlin-Chemie/ /Menarini, Polpharma, Medtronic, Bayer and Adamed.

AJ reports having received lecturer's honoraria and travel expenses from Servier, Krka, Berlin-Chemie/ /Menarini, Polpharma, Medtronic, Zentiva, Abbottt and Adamed.

\section{References}

1. Widecka K., Grodzicki T., Narkiewicz K., Tykarski A., Dziwura J. Zasady postępowania w nadciśnieniu tętniczym -2011 rok. Wytyczne Polskiego Towarzystwa Nadciśnienia Tętniczego. Nadciśnienie Tętnicze 2011; 15: 55-82.

2. Mancia G., Fagard R., Narkiewicz K. et al. 2013 ESH/ESC Guidelines for the management of arterial hypertension: the Task Force for the management of arterial hypertension of the European Society of Hypertension (ESH) and of the European Society of Cardiology (ESC). J Hypertens 2013; 31: 1281-1357.

3. Tykarski A., Narkiewicz K., Gaciong Z., Januszewicz A., Litwin M., Kostka-Jeziorny K. Guideliens for the management of hypertension. Arterial Hypertens 2015; 19: 58-83.

4. James P.A., Oparil S., Carter B.L. et al. 2014 evidence-based guideline for the management of high blood pressure in adults: report from the panel members appointed to the Eighth Joint National Committee (JNC 8). JAMA 2014; 311: 507-520.

5. Weber M.A., Schiffrin E.L., White W.B. et al. Clinical practice guidelines for the management of hypertension in the community a statement by the American Society of Hypertension and the International Society of Hypertension. J. Hypertens. 2014; 32: 3-15.

6. Bangalore S., Makani H., Radford M. et al. Clinical outcomes with beta-blockers for myocardial infarction: a meta-analysis of randomized trials. Am. J. Med. 2014; 127: 939-953.

7. Sarganas G., Knopf H., Grams D., Neuhauser H.K. Trends in antihypertensive medication use and blood pressure control among adults with hypertension in Germany. Am. J. Hypertens. 2015 (published ahead of print).

8. Zhou M., Daubresse M., Stafford R.S., Alexander G.C. National trends in the ambulatory treatment of hypertension in the United States, 1997-2012. PLoS One 2015; 10: e0119292.

9. Caceres M.C., Moyano P., Frainas H. et al. Trends in antihypertensive drug use in Spanish primary health care (1990-2012). Adv. Pharmacoepidemiol. Drug Saf. 2015; 4: 1-4.
10. Gu Q., Burt V.L., Dillon C.F., Yoon S. Trends in antihypertensive medication use and blood pressure control among United States adults with hypertension: the National Health And Nutrition Examination Survey, 2001 to 2010. Circulation 2012; 126: 2105-2114.

11. Prejbisz A., Klocek M., Gasowski J. et al. Factors associated with resistant hypertension in a large cohort of hypertensive patients: the Pol-Fokus study. Pol. Arch. Med. Wewn. 2015; 125: 249-259.

12. Mancia G., De Backer G., Dominiczak A. et al. 2007 Guidelines for the management of arterial hypertension: The Task Force for the Management of Arterial Hypertension of the European Society of Hypertension (ESH) and of the European Society of Cardiology (ESC). J. Hypertens. 2007; 25: 1105-1187.

13. Levey A.S., Coresh J., Greene T. et al. Using standardized serum creatinine values in the modification of diet in renal disease study equation for estimating glomerular filtration rate. Ann. Intern. Med. 2006; 145: 247-254.

14. Roberts W.C., Black H.R., Bakris G.L., Mason R.P., Giles T.D., Sulkes D.J. The editor's roundtable: revisiting the role of beta blockers in hypertension. Am. J. Cardiol. 2007; 100: 253-267.

15. Bradley H.A., Wiysonge C.S., Volmink J.A., Mayosi B.M., Opie L.H. How strong is the evidence for use of beta-blockers as firstline therapy for hypertension? Systematic review and meta-analysis. J. Hypertens. 2006; 24: 2131-2141.

16. Andell P., Erlinge D., Smith J.G. et al. Beta-blocker use and mortality in COPD patients after myocardial infarction: a Swedish nationwide observational study. J. Am. Heart Assoc. 2015; 4 (published ahead of print).

17. McGill J.B. Improving microvascular outcomes in patients with diabetes through management of hypertension. Postgrad. Med. 2009; 121: 89-101.

18. Rosendorff C., Lackland D.T., Allison M. et al. Treatment of hypertension in patients with coronary artery disease: a scientific statement from the American Heart Association, American College of Cardiology, and American Society of Hypertension. Hypertension 2015; 65: 1372-1407.

19. Andersson C., Shilane D., Go A.S. et al. Beta-blocker therapy and cardiac events among patients with newly diagnosed coronary heart disease. J. Am. Coll. Cardiol. 2014; 64: 247-252.

20. Bangalore S., Bhatt D.L., Steg P.G. et al. Beta-blockers and cardiovascular events in patients with and without myocardial infarction: post hoc analysis from the CHARISMA trial. Circ. Cardiovasc. Qual. Outcomes 2014; 7: 872-881.

21. Bangalore S., Steg G., Deedwania P. et al. Beta-blocker use and clinical outcomes in stable outpatients with and without coronary artery disease. JAMA 2012; 308: 1340-1349.

22. Law M.R., Morris J.K., Wald N.J. Use of blood pressure lowering drugs in the prevention of cardiovascular disease: meta-analysis of 147 randomised trials in the context of expectations from prospective epidemiological studies. BMJ 2009; 338: b1665.

23. Lindholm L.H., Carlberg B., Samuelsson O. Should beta blockers remain first choice in the treatment of primary hypertension? A meta-analysis. Lancet 2005; 366: 1545-1553. 